\title{
Trp53 inactivation in the tumor microenvironment promotes tumor progression by enhancing pro-inflammatory tumor stromal populations
}

\author{
Gang Guo', Luis Marrero², Augusto Ochoa', Yan Cui ${ }^{1,2^{*}}$ \\ From Society for Immunotherapy of Cancer 28th Annual Meeting \\ National Harbor, MD, USA. 8-10 November 2013
}

Inactivation of the tumor suppressor p53 is one of the leading causes of cancer as $p 53$ inactivation via somatic mutations occurs in $50 \%$ of human cancers and sometimes in fibroblasts within the tumor microenvironment (TME). Recent studies by our laboratory and others suggest that p53 inactivation promotes a pro-inflammatory host microenvironment - elevated serum inflammatory cytokines/ chemokines, enhanced Th17 cells, and augmented differentiation of myeloid cells, including myeloid derived suppressors (MDSCs). As chronic inflammation plays a vital role in tumor initiation, progression, and metastases, we hypothesized that $p 53$ inactivation in the TME favors tumorigenesis by promoting inflammation. To test our hypothesis and elucidate the cellular and molecular mechanisms by which $p 53$ inactivation augments proinflammation and tumor progression, we compared the growth of subcutaneously inoculated B16F1 melanoma with a functional p53 in p53null and WT mice. As expected, tumor growth in $p 53$ nullmice was greatly accelerated. Remarkably, the accelerated tumor growth in p53null hosts was associated with an extensive expansion of stromal populations, including various myeloid populations, as well as non-hematopoietic reticular fibroblastic cells (FRC) reminiscent of stromal cells of the secondary lymphoid organs (SLO), both within the TME and the secondary lymphoid tissues. Further cellular and molecular analyses revealed that these CD106hiCD54+GP38 +Sca-1lo/- FRCs, especially from $p 53$ null hosts, expressed high levels of pro-inflammatory cytokines/chemokines and immunosuppressive mediators that supported the survival and proliferation of various myeloid populations, including $\mathrm{CD} 11 \mathrm{~b}+\mathrm{Gr}-1+$ myeloid-derived suppressor cells (MDSCs).

'Sanely Scott Cancer Center, LSUHSC-NO, New Orleans, LA, USA

Full list of author information is available at the end of the article
Together, our results suggest that $p 53 \mathrm{null}$ stroma is highly immunosuppressive, which modulates host immunemicroenvironment via cytokine/chemokine and stromaimmune cell interaction and promotes tumor progression. This study underscores the immunological function of p53 in tumor suppression and broadens our appreciation of the $\mathrm{p} 53$ as a guardian and gatekeeper not only via inducing apoptosis and cellular senescence, but also via regulating the immunological microenvironment.

\section{Authors' details}

'Sanely Scott Cancer Center, LSUHSC-NO, New Orleans, LA, USA.

${ }^{2}$ Microbiology, Immunology, and Parasitology, LSUHSC-NO, New Orleans, LA, USA.

Published: 7 November 2013

doi:10.1186/2051-1426-1-S1-P189

Cite this article as: Guo et al:: Trp53 inactivation in the tumor microenvironment promotes tumor progression by enhancing pro-inflammatory tumor stromal populations. Journal for ImmunoTherapy of Cancer 2013 1(Suppl 1):P189.

Submit your next manuscript to BioMed Central and take full advantage of:

- Convenient online submission

- Thorough peer review

- No space constraints or color figure charges

- Immediate publication on acceptance

- Inclusion in PubMed, CAS, Scopus and Google Scholar

- Research which is freely available for redistribution 